\title{
Asymmetrical dimethylarginine and severity of erectile dysfunction and their impact on cardiovascular events in patients with acute coronary syndrome
}

Meryem Aktoz ${ }^{1}$, Tevfik Aktoz², Ersan Tatlı1, Mustafa Kaplan², Fatma Nesrin Turan³, Ahmet Barutçu1, Irfan Hüseyin Atakan², Muzaffer Demir , Armağan Altun ${ }^{1}$

1Department of Cardiology, School of Medicine, Trakya University, Edirne, Turkey 2Department of Urology, School of Medicine, Trakya University, Edirne, Turkey ${ }^{3}$ Department of Biostatistics, School of Medicine, Trakya University, Edirne, Turkey 4Department of Internal Medicine, School of Medicine, Trakya University, Edirne, Turkey

Submitted: 7 August 2009

Accepted: 24 September 2009

Arch Med Sci 2010; 6, 2: 168-175

DOI: 10.5114 /aoms.2010.13888

Copyright (c) 2010 Termedia \& Banach

\section{Abstract}

Introduction: Coronary artery disease (CAD) and vascular erectile dysfunction (ED) are related to endothelial dysfunction. Elevated asymmetrical dimethylarginine (ADMA) levels and ED are common in patients with increased cardiovascular risk. Our aim was to investigate whether ADMA has a predictive role for major adverse cardiovascular events (MACE) in acute coronary syndrome (ACS). The secondary aim of this study was to investigate whether severity of ED predicts MACE in these patients.

Material and methods: Follow-up data were available for severity of ED in 71 patients with ACS. Plasma ADMA levels were determined by ELISA in 57 patients. Erectile dysfunction was assessed by the International Index of Erectile Function- 6 (IIEF-6) score. Major adverse cardiovascular events (reinfarction, all-cause hospitalisation, stroke and all-cause death) was evaluated after a median of 10 months.

Results: Severe ED had no significantly increased hazard ratio for cardiovascular events compared with mild, mild to moderate, and moderate ED $(0.259[95 \% \mathrm{Cl}$ $0.041-1.6$ ], $p=0.147 ; 0.605$ [95\% Cl 0.095-3.8], $p=0.594 ; 0.980$ [95\% Cl 0.233-4.1], $p=0.978$; and 0.473 [95\% Cl 0.052-1.3], $p=0.508$ ). The patients who had ADMA levels $\geq 0.32 \mu \mathrm{mol} / \mathrm{l}$ had no significantly increased hazard ratio for cardiovascular events compared with patients who had ADMA levels $<0.32 \mu \mathrm{mol} / \mathrm{l}(2.018[95 \% \mathrm{Cl}$ 0.615-6.6], $p=0.247$ ).

Conclusions: Severity of ED and ADMA did not increase the risk of cardiovascular events in follow-up patients with ACS in our study. Larger prospective studies are necessary to evaluate whether ADMA predicts cardiovascular events in patients with ACS.

Key words: acute coronary syndrome, asymmetric dimethylarginine, erectile dysfunction, major adverse cardiovascular events.

\section{Introduction}

Erectile dysfunction (ED) is associated with increased vascular risk of coronary heart disease and stroke [1]. Increased prevalence rates of ED have been reported in patients with vascular disorders such as myocardial infarction and stroke [2]. Men with ED have a two-fold increased risk for acute myocardial infarction [3]. Because ED is a marker of subclinical

\author{
Corresponding author: \\ Meryem Aktoz, MD \\ Department of Cardiology \\ School of Medicine \\ Trakya University \\ Edirne 22030, Turkey \\ Phone: 902842357641 \\ Fax: 902842352730 \\ E-mail: \\ meryemaktoz1@yahoo.com
}


coronary artery disease (CAD), many ED patients carry a risk of acute coronary syndrome (ACS). Although the association between cardiovascular risk factors and ED is well established, the predictive role of ED for future cardiovascular events in CAD patients who present with ACS is not known clearly.

Asymmetrical dimethylarginine (ADMA) has recently aroused interest as an endogenous competitive inhibitor of nitric oxide synthases and an independent marker for cardiovascular disease [4]. Generated ADMA is dependent on the extent of arginine methylation in proteins and in the rates of protein turnover and it is extensively metabolized by dimethylarginine dimethylaminohydrolase [5]. It has the potential to produce considerable biological effects, particularly in the endothelial system. Over the last years, several studies have suggested that plasma concentrations of ADMA provide a marker of risk for endothelial dysfunction [6]. Asymmetrical dimethylarginine levels are significantly elevated in men who have early stage coronary atherosclerosis and ED [7]. Assessment of ADMA might aid cardiovascular risk assessment. We investigated whether ADMA has a predictive role for major adverse cardiovascular events (MACE) in CAD patients who presented with ACS. The secondary aim of this study was to investigate whether severity of ED predicts MACE in these patients.

\section{Material and methods}

A total of 121 men who presented with ACS and underwent coronary angiography were prospectively enrolled between January 2007 and July 2007 for this study. Thirty-one patients refused participation or returned the International Index of Erectile Function-6 (IIEF-6) questionnaire incomplete. After evaluation of exclusion criteria (heart failure, end stage renal failure, severe valvular heart disease, concomitant chronic severe disease), 90 patients were enrolled into the ongoing study. In 20 patients laboratory values for ADMA were missing and 13 patients' follow-up data of MACE were not available. Asymmetrical dimethylarginine analysis was performed for the remaining 57 patients. For analysis of ED severity, 19 patients' follow-up data of MACE were not available. The remaining 71 subjects with complete baseline and follow-up data were included in the analysis.

Inclusion criteria for ACS were: chest pain consistent with myocardial ischaemia, elevation of troponin-I or creatine kinase above upper limit of normal, and one of the following findings: electrocardiographic evidence of ischaemia, or wall motion abnormality. At the time of inclusion, demographic data, clinical characteristics and current medications were recorded. All patients were evaluated with physical examination and underwent laboratory tests, including lipid profile and fasting glucose. Risk factors were defined as follows: hypertension as blood pressure $>140 / 90 \mathrm{~mm} \mathrm{Hg}$ or taking antihypertensive drugs; hypercholesterolaemia as total cholesterol level $>190 \mathrm{mg} / \mathrm{dl}$ and LDL cholesterol level $>130 \mathrm{mg} / \mathrm{dl}$; diabetes as fasting glucose level $>125 \mathrm{mg} / \mathrm{dl}$ or taking antidiabetic drugs. The study protocol was approved by the Local Ethics Committee and all patients gave informed consent.

\section{Assessment of erectile dysfunction}

Erectile dysfunction was assessed by the IIEF-6 score [8]. All men were asked to complete the IIEF questionnaire. Erectile function is addressed by 6 questions. Each question is scored 0 to 5 . Erectile dysfunction is defined as value $<26$. The severity of ED was classified into 5 categories: no ED (IIEF score 26 to 30), mild (IIEF score 22 to 25), mild to moderate (IIEF score 17 to 21), moderate (IIEF score 11 to 16$)$, and severe (IIEF score < 10) [8].

\section{Assessment of coronary artery involvement}

Coronary angiography was carried out in all patients by the Judkins standard technique. Significant angiographic narrowing was defined as $>50 \%$ diameter stenosis. Coronary artery disease was scored with 1-2-3 vessel disease. Our study included cases with ACS, and because of acute total occlusion, previously modified Gensini score was used for coronary artery involvement [9].

\section{Laboratory investigations}

After an overnight fast, venous blood was collected and serum separated and stored at $-70^{\circ} \mathrm{C}$ until batch analysis. All blood samples were taken within 1 week of diagnosis of ACS and before coronary angiography. Blood levels of blood glucose, total cholesterol, HDL cholesterol, LDL cholesterol and triglycerides were measured by standard laboratory methods. ADMA was analysed by the ELISA method (ADMA direct ELISA, Immundiagnostik AG, Bensheim, Germany) according to the manufacturer's guidelines.

\section{Study end points and follow-up}

The study end point was the occurrence of a first MACE consisting of reinfarction, re-hospitalisation, stroke and all cause death. All patients were then prospectively followed by office visit or by telephone contact at 3-month intervals for the occurrence of first MACE. Outcome was evaluated by 2 observers (M. A., A. B.) who were blinded with respect to the patients' baseline clinical and laboratory data.

\section{Statistical analysis}

Continuous data are presented as medians (minmax values) for both ADMA and IIEF-6 score. 
Categorical data are given as counts (percentages). Mann-Whitney $U$ test was applied for univariate comparison of continuous data and Spearman rank correlation for assessment of associations between continuous variables. ROC analysis was used for ADMA cut-off values. Event-free survival rates until the first cardiovascular adverse event according to ADMA levels (ROC analysis) and IIEF score were calculated using the Kaplan-Meier method and compared by the log rank test. Multivariate Cox proportional hazards analysis was used to assess the independent effect of ADMA and IIEF on the composite end point and to adjust for potential confounders. Continuous variables were included as confounders if these variables were associated with ADMA and IIEF according to Spearman rank correlation coefficients. Categorical variables were entered into the model if they influenced ADMA and IIEF according to univariate analysis. In addition, adjustment for traditional cardiovascular risk factors was performed. Results of the Cox proportional hazards model are presented as hazard ratio and 95\% confidence interval $(\mathrm{Cl})$ as well as survival curves according to cut-off values of ADMA and IIEF. $P$ values $<0.05$ were considered to indicate statistical significance.

According to a retrospective power analysis for ADMA level in patients, when 57 patients and $H R=2.018$ are used, power is calculated as 0.275 $(\alpha=0.05)$. Data were analysed using NCSS 2008 Demo for Windows (NCSS, Kaysville, UT, USA).

\section{Results}

Ninety patients were eligible for the study. In 20 patients laboratory values for ADMA were missing and 13 patients' follow-up data of MACE were not available. Asymmetrical dimethylarginine analysis was performed for the remaining 57 patients. For analysis of ED severity, 19 patients' follow-up data of MACE were not available. The remaining 71 subjects with complete baseline and follow-up data were included in the analysis. Follow-up duration was median 10 months (range: 1-13 months).

\section{Asymmetrical dimethylarginine and survival}

Median ADMA plasma concentration of all patients was $0.50 \mu \mathrm{mol} / \mathrm{I}(\mathrm{IQR}, 0.06$ to 1.41). Factors potentially influencing ADMA concentrations such as the presence of risk factors of atherosclerosis, medication, coronary vessels involvement, and revascularisation were not significantly different (Table I). Asymmetrical dimethylarginine was elevated in the patients without diabetes mellitus and the group without antidiabetic therapy and correlated negatively with age and Gensini score (Table II). During follow-up, 5.3\% reinfarction, 12.3\% hospitalisation, and $8.8 \%$ all-cause death occurred in 57 patients, and the revascularisation rate was $63.2 \%$. When the cut-off value of ADMA $0.32 \mu \mathrm{mol} / \mathrm{l}$ was accepted according to ROC analysis, $>0.32$ $\mu \mathrm{mol} / \mathrm{l}$ yielded a sensitivity of $70 \%$ and a specificity of $28 \%$ for detecting CAD which presented ACS. Thus, according to ADMA cut-off value $0.32 \mu \mathrm{mol} / \mathrm{l}$, 57 subjects were divided into 2 groups. Twenty-nine percent MACE in the patients who had ADMA levels $<0.32 \mu \mathrm{mol} / /$ and $17.5 \%$ MACE in other patients occurred during the follow-up period ( $p=0.236$, $\chi^{2}=1.405$, log rank test). The patients who had ADMA levels $\geq 0.32 \mu \mathrm{mol} / \mathrm{l}$ had no significantly increased hazard ratio for cardiovascular events compared with patients who had ADMA levels $<0.32 \mu \mathrm{mol} / \mathrm{l}$ after adjustment for possible confounders (2.018 [95\% Cl 0.615-6.626], $p=0.247$ (Table III).

\section{Severity of erectile dysfunction and survival}

During follow-up 20 (28.5\%) MACE occurred in 71 patients including $7.1 \%$ reinfarction, $14.3 \%$ hospitalisation, and $7.1 \%$ all-cause death, and the revascularisation rate was $64.3 \%$. When patients were divided into 5 groups according to severity of ED, no ED had no significantly increased hazard ratio for cardiovascular events compared with mild, mild to moderate, moderate ED, and severe ED after adjustment for possible confounders (0.259 [95\% Cl 0.041-1.610], $p=0.147 ; 0.605$ [95\% Cl 0.0953.843], $p=0.594 ; 0.980$ [95\% Cl 0.233-4.121], $p=0.978 ; 0.473$ [95\% Cl 0.052-1.345], $p=0.508$, respectively). (According to multivariate Cox regression analysis) (Table IV).

\section{Discussion}

Our findings showed that serum ADMA concentrations and severity of ED did not predict major cardiovascular events after adjustment of confounder factors in patients with CAD who presented with ACS in this study population. No difference, in terms of serum ADMA and severity of $E D$, was seen between the MACE group and the group without MACE.

Over the last decade, several studies have shown that circulating concentrations of ADMA can be influenced by many factors. Treatment with rosuvastatin [10], rosiglitazone, metformin, ACE inhibitors and AT-2 receptor blockers have decreased ADMA concentrations in humans [11, 12]. In addition, ADMA is a well characterized marker that has been associated with many traditional risk factors and vascular disorders, as demonstrated for hypertension [13], hyperhomocysteinaemia [14], peripheral artery disease [15], and stroke [16]. Barylski et al. [17] showed that renal failure may be related to impaired endothelial function. Vallance et al. [18] demonstrated that accumulation of 
Table I. Median plasma concentrations (interquartile range) of ADMA and IIEF score grouped according to categorical baseline variables

\begin{tabular}{|c|c|c|c|c|c|c|}
\hline & $N$ & ADMA $[\mu \mathrm{mol} / \mathrm{l}]$ & $P$ value & $N$ & IIEF (score) & $P$ value \\
\hline \multicolumn{7}{|l|}{ Risk factors } \\
\hline \multicolumn{7}{|c|}{ Hypertension } \\
\hline Yes & 21 & $0.44(0.06-1.30)$ & & 26 & $18(1-30)$ & \\
\hline No & 36 & $0.55(0.09-1.41)$ & 0.155 & 44 & $20(1-30)$ & 0.363 \\
\hline \multicolumn{7}{|c|}{ Diabetes mellitus } \\
\hline Yes & 9 & $0.16(0.06-0.84)$ & & 15 & $11(1-26)$ & \\
\hline No & 48 & $0.54(0.09-1.41)$ & 0.001 & 53 & $21(1-30)$ & 0.002 \\
\hline \multicolumn{7}{|c|}{ Hyperlipidaemia } \\
\hline Yes & 6 & $0.34(0.08-0.71)$ & & 7 & $26(15-30)$ & \\
\hline No & 51 & $0.50(0.06-1.41)$ & 0.233 & 63 & $19(1-30)$ & 0.116 \\
\hline \multicolumn{7}{|c|}{ Smoking current } \\
\hline Yes & 33 & $0.55(0.09-1.41)$ & & 41 & $20(1-30)$ & \\
\hline No & 24 & $0.45(0.06-1.28)$ & 0.070 & 29 & $15(1-30)$ & 0.031 \\
\hline \multicolumn{7}{|c|}{ Smoking former } \\
\hline Yes & 46 & $0.50(0.08-1.41)$ & & 57 & $19(1-30)$ & \\
\hline No & 11 & $0.47(0.06-1.28)$ & 0.537 & 13 & $20(1-30)$ & 0.867 \\
\hline \multicolumn{7}{|l|}{ Medication } \\
\hline \multicolumn{7}{|c|}{$\beta$-Blocker therapy } \\
\hline Yes & 14 & $0.52(0.08-1.13)$ & & 16 & $24(1-30)$ & \\
\hline No & 43 & $0.47(0.06-1.41)$ & 0.882 & 54 & $18.5(1-30)$ & 0.187 \\
\hline \multicolumn{7}{|c|}{ ACE inhibitors therapy } \\
\hline Yes & 15 & $0.49(0.06-1.30)$ & & 17 & $21(1-30)$ & \\
\hline No & 42 & $0.52(0.08-1.41)$ & 0.906 & 53 & $19(1-30)$ & 0.283 \\
\hline \multicolumn{7}{|c|}{ AT2 receptor blocker therapy } \\
\hline Yes & 5 & $0.43(0.08-0.97)$ & & 7 & $22(1-30)$ & \\
\hline No & 52 & $0.52(0.06-1.41)$ & 0.401 & 63 & $19(1-30)$ & 0.549 \\
\hline \multicolumn{7}{|c|}{ Calcium antagonist therapy } \\
\hline Yes & 4 & $0.78(0.38-1.13)$ & & 4 & $15.5(1-28)$ & \\
\hline No & 53 & $0.49(0.06-1.41)$ & 0.142 & 66 & $19.5(1-30)$ & 0.470 \\
\hline \multicolumn{7}{|c|}{ Diuretic therapy } \\
\hline Yes & 1 & $1.30(1.30-1.30)$ & & 1 & $30(30-30)$ & \\
\hline No & 56 & $0.49(0.06-1.41)$ & 0.070 & 69 & $19(1-30)$ & 0.143 \\
\hline \multicolumn{7}{|c|}{ Statin therapy } \\
\hline Yes & 5 & $0.58(0.28-1.13)$ & & 7 & $26(9-30)$ & \\
\hline No & 52 & $0.49(0.06-1.41)$ & 0.671 & 63 & $19(1-30)$ & 0.242 \\
\hline \multicolumn{7}{|c|}{ Acetylsalicylic acid therapy } \\
\hline Yes & 18 & $0.46(0.06-1.41)$ & & 20 & $21.5(1-30)$ & \\
\hline No & 39 & $0.54(0.12-1.28)$ & 0.589 & 50 & $19(1-30)$ & 0.293 \\
\hline \multicolumn{7}{|c|}{ Clopidogrel therapy } \\
\hline Yes & 5 & $0.50(0.28-1.13)$ & & 6 & $20.5(1-30)$ & \\
\hline No & 52 & $0.49(0.06-1.41)$ & 0.838 & 64 & $19(1-30)$ & 0.976 \\
\hline
\end{tabular}


Table I. Median plasma concentrations (interquartile range) of ADMA and IIEF score grouped according to categorical baseline variables

\begin{tabular}{|c|c|c|c|c|c|c|}
\hline & $N$ & ADMA [ $\mu \mathrm{mol} / \mathrm{l}]$ & $P$ value & $N$ & IIEF (score) & $P$ value \\
\hline \multicolumn{7}{|c|}{ Anticoagulant therapy } \\
\hline Yes & 1 & $0.49(0.49-0.49)$ & & 1 & $24(24-24)$ & \\
\hline No & 56 & $0.50(0.06-1.41)$ & 0.982 & 69 & $19(1-30)$ & 0.686 \\
\hline \multicolumn{7}{|c|}{ Oral antidiabetic therapy } \\
\hline Yes & 6 & $0.06(0.08-0.84)$ & & 9 & $12(1-26)$ & \\
\hline No & 51 & $0.54(0.06-1.41)$ & 0.017 & 61 & $20(1-30)$ & 0.032 \\
\hline \multicolumn{7}{|c|}{ Insulin therapy } \\
\hline Yes & 3 & $0.15(0.06-0.84)$ & & 3 & $1(1-18)$ & \\
\hline No & 54 & $0.50(0.08-1.41)$ & 0.259 & 67 & $20(1-30)$ & 0.058 \\
\hline \multicolumn{7}{|c|}{ Coronary vessels involvement } \\
\hline \multicolumn{7}{|c|}{ One-vessel disease } \\
\hline Yes & 17 & $0.54(0.16-1.28)$ & & 21 & $24(1-30)$ & \\
\hline No & 40 & $0.47(0.06-1.41)$ & 0.958 & 49 & $18(1-30)$ & 0.053 \\
\hline \multicolumn{7}{|c|}{ Two-vessel disease } \\
\hline Yes & 18 & $0.61(0.18-1.26)$ & & 20 & $18.5(1-30)$ & \\
\hline No & 39 & $0.47(0.06-1.41)$ & 0.066 & 50 & $20(1-30)$ & 0.527 \\
\hline \multicolumn{7}{|c|}{ Three-vessel disease } \\
\hline Yes & 22 & $0.35(0.06-1.41)$ & & 29 & $18(1-30)$ & \\
\hline No & 35 & $0.55(0.16-1.28)$ & 0.071 & 41 & $20(1-30)$ & 0.222 \\
\hline \multicolumn{7}{|c|}{ Total occlusion } \\
\hline Yes & 13 & $0.38(0.06-1.10)$ & & 15 & $18(1-30)$ & \\
\hline No & 44 & $0.54(0.09-1.41)$ & 0.068 & 55 & $20(1-30)$ & 0.499 \\
\hline \multicolumn{7}{|c|}{ Revascularisation } \\
\hline Yes & 36 & $0.43(0.06-1.30)$ & & 45 & $21(1-30)$ & \\
\hline No & 21 & $0.54(0.16-1.41)$ & 0.317 & 25 & $15(1-30)$ & 0.056 \\
\hline
\end{tabular}

Table II. Baseline characteristics and Spearman correlation coefficients ( $p$ value) for ADMA and IIEF score and continuous variables of acute coronary syndrome

\begin{tabular}{|c|c|c|c|c|c|c|}
\hline & Median (min-max) & $\begin{array}{c}\text { ADMA } \\
\text { (R) }\end{array}$ & $P$ value & Median (min-max) & $\begin{array}{l}\text { IIEF score } \\
\text { (R) }\end{array}$ & $P$ value \\
\hline Age [year] & $58(35-79)$ & -0.301 & 0.02 & $58(35-79)$ & -0.635 & 0.000 \\
\hline Body mass index $\left[\mathrm{kg} / \mathrm{m}^{2}\right]$ & $26.22(18.8-42.59)$ & -0.137 & 0.31 & $26.2(18.8-42.6)$ & 0.139 & 0.251 \\
\hline Cholesterol [mg/dl] & $182(86-278)$ & -0.279 & 0.47 & $177.5(86-326)$ & 0.340 & 0.291 \\
\hline Triglycerides [mg/dl] & $128(50-410)$ & 0.007 & 0.96 & $132(40-410)$ & 0.071 & 0.573 \\
\hline LDL cholesterol [mg/dl] & $113(29-214)$ & -0.282 & 0.04 & $112(29-320)$ & 0.056 & 0.658 \\
\hline HDL cholesterol [mg/dl] & $36(22-50)$ & -0.342 & 0.01 & $35(22-50)$ & 0.202 & 0.116 \\
\hline Ejection fraction [\%] & $50(57-30.74)$ & 0.102 & 0.48 & $57(30-74)$ & 0.080 & 0.541 \\
\hline Gensini score & $33(7-117)$ & -0.291 & 0.03 & $39(7-122)$ & -0.309 & 0.009 \\
\hline IIEF score & $21(1-30)$ & 0.247 & 0.06 & $19(1-30)$ & - & - \\
\hline $\mathrm{ADMA}[\mu \mathrm{mol} / \mathrm{l}]$ & $0.50(0.06-1.41)$ & - & - & & & \\
\hline
\end{tabular}


Table III. Cox regression analysis assessing the multivariate hazard ratio for ADMA

\begin{tabular}{|lcc|}
\hline & $\begin{array}{c}\text { Hazard ratio } \\
(95 \% \mathrm{Cl})\end{array}$ & $P$ value \\
\hline ADMA $<0.32 \mu \mathrm{mol} / \mathrm{l}$ & 1 & \\
\hline ADMA $\geq 0.32 \mu \mathrm{mol} / \mathrm{l}$ & $2.018(0.615-6.626)$ & 0.247 \\
\hline
\end{tabular}

Cut-off value 0.32 Umol/l according to ROC analysis (sensitivity $70 \%$, specificity 27\%). Multivariate model: adjustment for age, total cholesterol, LDL cholesterol, fasting blood glucose and Gensini score

endogenous ADMA, as an indicator of endothelial dysfunction, is associated with chronic renal failure.

In our study, factors potentially influencing ADMA concentrations and prognosis after ACS were not significantly different, such as the presence of risk factors of atherosclerosis, medication, coronary vessels involvement, revascularisation, and valve disease. In our study, ADMA serum concentrations were low in diabetic patients. This paradoxical finding could in part be explained by administration of oral antidiabetic therapy in half of the diabetic population. Metformin and thiazolidinediones reduce ADMA levels $[19,20]$. Furthermore, our results indicate that hypertension, hyperlipidaemia, smoking, medications including $\beta$-blocker therapy, ACE inhibitors and AT-2 blocker therapy, statins, diuretics, calcium channel blockers and antiaggregant therapy did not influence serum ADMA concentrations. Asymmetrical dimethylarginine concentrations were not different in patients on statin therapy or antihypertensive therapy in the present cohort.

Since the demonstration that concentration of ADMA acts as a marker of endothelial dysfunction, circulating levels of ADMA have been related to the presence of coronary artery disease [21] and the occurrence of acute coronary syndrome [22]. Schnabel et al. [23] showed that circulating ADMA adds independent prognostic information in patients with CAD. Valkonen et al. [21] demonstrated that high concentrations of ADMA in serum are associated with an increased risk of acute coronary events among non-smoking middleaged men, especially in men with previous coronary heart disease. A recent study in patients with acute $\mathrm{MI}$ reported that the baseline ADMA level has prognostic value for mortality after acute myocardial infarction [24]. Asymmetrical dimethylarginine was not associated with future cardiovascular events in the present study. This could be explained by the fact that our study sample was small and all male. Meinitzer et al. [25] demonstrated that ADMA concentrations predict all-cause and cardiovascular mortality in individuals with stable and acute CAD. A difference of their study was inclusion of patients with stable CAD.

Our trial is the first study in the literature to investigate whether severity of ED predicts major
Table IV. Cox regression analysis assessing the multivariate hazard ratio for IIEF scoring

\begin{tabular}{|lcc|}
\hline & \multicolumn{1}{|c|}{$\begin{array}{c}\text { Hazard ratio } \\
(95 \% \text { Cl) }\end{array}$} & P value \\
\hline No ED (IIEF score 26 to 30) & 1 & \\
\hline $\begin{array}{l}\text { Mild ED } \\
\text { (IIEF score 22 to 25) }\end{array}$ & $0.259(0.041-1.610)$ & 0.147 \\
\hline $\begin{array}{l}\text { Mild to moderate ED } \\
\text { (IIEF score 17 to 21) }\end{array}$ & $0.605(0.095-3.843)$ & 0.594 \\
\hline $\begin{array}{l}\text { Moderate ED } \\
\text { (IIEF score 11 to 16) }\end{array}$ & $0.980(0.233-4.121)$ & 0.978 \\
\hline $\begin{array}{l}\text { Severe ED } \\
\text { (IIEF score 1 to 10) }\end{array}$ & $0.473(0.052-1.345)$ & 0.508 \\
\hline
\end{tabular}

Multivariate model: adjustment for age, diabetes mellitus, current smoking, oral antidiabetic therapy

cardiovascular events in patients with coronary artery disease with ACS. Vascular disease and ED have similar pathogenic involvement of the nitric oxide pathway leading to impairment of endothelium dependent vasodilatation and structural vascular abnormalities [26, 27]. Montorsi et al. identified ED as a predictor of acute coronary syndromes [28]. They showed that ED occurred before CAD symptoms in $67 \%$ of patients with ED. Thus, they reinforced that ED might predict the presence of subclinical vulnerable plaque. Ponholzer et al. [29] showed that moderate-to-severe ED was calculated to increase the 10 -year relative risk of developing CAD by $65 \%$ and stroke by $43 \%$. Another trial showed that ED significantly predicted cardiac events [30]. Montorsi et al. [9] found that severe ED was more frequent in patients with multi-vessel as compared to single vessel disease. Thus, severe ED should raise questions about prognosis in patients with CAD. We found that severity of ED did not predict future cardiovascular events in patients with ACS. Recently published data have demonstrated that ED is a powerful predictor of cardiovascular morbidity and mortality in diabetic patients with silent CAD [31]. Large prospective studies are necessary to evaluate whether ED predicts cardiovascular events in patients with ACS.

Our study is limited by the relatively small sample size. The relatively small number of male patients could be the reason why ADMA and severity of ED are not predictive in our study. Bae et al. [32] found a significant decrease in ADMA levels after 2 weeks of medical therapy for ACS. Because of this we took blood samples within 1 week after diagnosis of ACS before coronary angiography. Although the majority of published methods for determination of plasma concentrations of ADMA are based on high performance liquid chromatography (HPLC), we determined ADMA by a recently atracted ELISA method that is suitable for the determination of 
ADMA in large sample series to be analysed more quickly than HPLC [33]. It may be a limitation of our study. Additionally, only male patients participated in the study, which is a further limitation. A recent study found that a $0.15 \mu \mathrm{mol} / /$ increase in baseline ADMA levels was associated with approximately $30 \%$ increase in incident cardiovascular risk in 880 healthy women [34]. However, whether ADMA concentrations are different in males and females with ACS is not known. After performing power analysis in our study we considered that large prospective studies, also including female patients, are necessary to evaluate whether ADMA predicts cardiovascular events in patients with ACS.

In conclusion, the results of this prospective study suggest that ADMA and severity of ED did not predict future cardiovascular events in this patient group. Larger prospective studies with longer follow-up are necessary to evaluate whether ADMA and ED predict MACE in patients with ACS.

\section{References}

1. Ponholzer A, Temml C, Obermayr R, Wehrberger C, Madersbacher $\mathrm{S}$. Is erectile dysfunction an indicator for increased risk of coronary heart disease and stroke? Eur Urol 2005; 48: 512-8.

2. Bomez-Caminero A, Vannaooagari V. Is erectile dysfunction predictive of peripheral vascular disease? Aging Male 2003; 6: 217-21.

3. Blumentals WA, Gomez-Caminero A, Joo S, Vannappagari V. Should erectile dysfunction be considered as a marker for acute myocardial infarction? Results from a retrospective cohort study. Int I Impot Res 2004; 16: 350-3.

4. Vallance P, Leone A, Calver A, Collier J, Moncada S. Endogenous dimethylarginine as an inhibitor of nitric oxide synthesis. J Cardiovasc Pharmacol 1992; 20 Suppl 12: S60-2.

5. McBride AE, Silver PA. State of the Arg: protein methylation at arginine comes of age. Cell 2001; 106: 5-8.

6. Boger RH, Bode-Boger SM, Szuba A, et al. Assymmetric dimethylarginine (ADMA): a novel risk factor for endothelial dysfunction: its role in hypercholesterolemia. Circulation 1998; 98: 1842-47.

7. Elesber AA, Solomon H, Lennon RJ, et al. Coronary endothelial dysfunction is associated with erectile dysfunction and elevated asymmetric dimethylarginine in patients with early atherosclerosis. Eur Heart J 2006; 27: 824-31

8. Cappelleri JC, Rosen RC, Smith MD, Mishra A, Osterloh IH. Diagnostic evaluation of the erectile function domain of the International Index of Erectile Function. Urology 1999; 54: 346-51.

9. Montorsi P, Ravagnani PM, Galli S, et al. Association between erectile dysfunction and coronary artery disease. Role of coronary clinical presentation and extent of coronary vessels involvement: the COBRA trial. Eur Heart J 2006; 27: 2632-9.

10. Lu TM, Ding YA, Leu HB, Yin WH, Sheu WH, Chu KM. Effect of rosuvastatin on plasma levels of asymmetric dimethylarginine in patients with hypercholesterolemia. Am J Cardiol 2004; 94: 157-61.
11. Asagami T, Abbasi $F$, Stuelinger $M$, et al. Metformin treatment lowers asymmetric dimethylarginine concentrations in patients with type 2 diabetes. Metabolism 2002; 51: 843-6.

12. Chen JW, Hsu NW, Wu TC, Lin SJ, Chang MS. Long-term angiotensin-converting enzyme inhibition reduces plasma asymmetric dimethylarginine and improves endothelial nitric oxide bioavailability and coronary microvascular function in patients with syndrome X. Am J Cardiol 2002; 90: 974-82.

13. Surdacki A, Nowicki M, Sandmann J, et al. Reduced urinary excretion of nitric oxide metabolites and increased plasma levels of asymmetric dimethylarginine in men with essential hypertension. J Cardiovasc Pharmacol 1999; 33: 652-8.

14. Sydow K, Schwedhelm E, Arakawa N, et al. ADMA andoxidative stress are responsible for endothelial dysfunction in hyperhomocyst(e)inemia: effects of L-arginine and B vitamins. Cardiovasc Res 2003; 57: 244-52.

15. Böger RH, Bode-Böger SM, Thiele W, Junker W, Alexander K, Frölich JC. Biochemical evidence for impaired nitric oxide synthesis in patients with peripheral arterial occlusive disease. Circulation 1997; 95: 2068-74.

16. Yoo JH, Lee SC. Elevated levels of plasma homocyst(e)ine and asymmetric dimethylarginine in elderly patients with stroke. Atherosclerosis 2001; 158: 425-30.

17. Barylski M, Banach M, Mikhailidis DP, Pawlicki L, Kowalski J. Decreased kidney function as a risk factor for cardiovascular events in subjects with metabolic syndrome-a pilot study. Arch Med Sci 2008; 4: 417-23.

18. Vallance P, Leone A, Calver A, Collier J, Moncada S. Accumulation of an endogenous inhibitor of nitric oxide synthesis in chronic renal failure. Lancet 1992; 339: 572-5.

19. Asagami T, Abbasi F, Stuelinger M, et al. Metformin treatment lowers asymmetric dimethylarginine concentrations in patients with type 2 diabetes. Metabolism 2002; 51: 843-6.

20. Lin KY, Ito A, Asagami T, et al. Impaired nitric oxide synthase pathway in diabetes mellitus: role of asymmetric dimethylarginine and dimethylarginine dimethylaminohydrolase. Circulation 2002; 106: 987-92.

21. Lu TM, Ding YA, Charng MJ, Lin SJ. Asymmetrical dimethylarginine: a novel risk factor for coronary artery disease. Clin Cardiol 2003; 26: 458-64.

22. Valkonen VP, Päivä H, Salonen JT, et al. Risk of acute coronary events and serum concentration of asymmetrical dimethylarginine. Lancet 2001; 358: 2127-8.

23. Schnabel R, Blankenberg S, Lubos E, et al. Asymmetric dimethylarginine and the risk of cardiovascular events and death in patients with coronary artery disease: results from the AtheroGene Study. Circ Res 2005; 97: e53-9.

24. Zeller M, Korandji C, Guilland JC, et al. Impact of asymmetric dimethylarginine on mortality after acute myocardial infarction. Arterioscler Thromb Vasc Biol 2008; 28: 954-60.

25. Meinitzer A, Seelhorst U, Wellnitz B, et al. Asymmetrical dimethylarginine independently predicts total and cardiovascular mortality in individuals with angiographic coronary artery disease (the Ludwigshafen Risk and Cardiovascular Health study). Clin Chem 2007; 53: 273-83.

26. Azadzoi KM, Goldstein I. Erectile dysfunction due to atherosclerotic vascular disease: the development of an animal model. J Urol 1992; 147: 1675-81.

27. Solomon H, Man JW, Jackson G. Erectile dysfunction and the cardiovascular patient: endothelial dysfunction is the common denominator. Heart 2003; 89: 251-3.

28. Montorsi F, Briganti A, Salonia A, et al. Erectile dysfunction prevalence, time of onset and association with risk factors 
in 300 consecutive patients with acute chest pain and angiographically documented coronary artery disease. Eur Urol 2003; 44: 360-5.

29. Ponholzer A, Temml C, Obermayr R, Wehrberger C, Madersbacher $\mathrm{S}$. Is erectile dysfunction an indicator for increased risk of coronary heart disease and stroke? Eur Urol 2005; 48: 512-8.

30. Thompson IM, Tangen CM, Goodman PJ, Probstfield JL, Moinpour CM, Coltman CA. Erectile dysfunction and subsequent cardiovascular disease. JAMA 2005; 294 : 2996-3002.

31. Gazzaruso C, Solerte SB, Pujia A, et al. Erectile dysfunction as a predictor of cardiovascular events and death in diabetic patients with angiographically proven asymptomatic coronary artery disease: a potential protective role for statins and 5-phosphodiesterase inhibitors. J Am Coll Cardiol 2008; 51: 2040-4.

32. Bae SW, Stühlinger MC, Yoo HS, et al. Plasma asymmetric dimethylarginine concentrations in newly diagnosed patients with acute myocardial infarction or unstable angina pectoris during two weeks of medical treatment. Am J Cardiol 2005; 95: 729-33.

33. Schulze F, Wesemann R, Scwedhelm E, et al. Determination of asymmetric dimethylarginine (ADMA) using a novel ELISA assay. Clin Chem Lab Med 20004; 42: 1377-83.

34. Leong T, Zylberstein D, Graham I, et al. Swedish-IrishNorwegian Collaboration. Asymmetric dimethylarginine independently predicts fatal and nonfatal myocardial infarction and stroke in women: 24-year follow-up of the population study of women in Gothenburg. Arterioscler Thromb Vasc Biol 2008; 28: 961-7. 